\title{
Biossegurança na assistência de enfermagem ao paciente no centro cirúrgico em tempos de pandemia Covid-19
}

\author{
Biosafety in nursing care to the patient in the surgical center in times of pandemic Covid-19 \\ Bioseguridad en la atención de enfermería al paciente en el centro quirúrgico en tiempos de \\ pandemia Covid-19
}

Lucas Ribeiro de Freitas $^{1 *}$, Clarice Souza Serafim ${ }^{1}$, José Luís Silva dos Santos ${ }^{1}$, Douglas Henrique da Silva Ferreira ${ }^{1}$, Anny Karoline de Oliveira Aquino ${ }^{1}$, Renata Natália Jovelina da Silva Montenegro ${ }^{1}$, Wanuska Munique Portugall ${ }^{1}$, Lenio José de Pontes Costa ${ }^{1}$, Filipe Almeida de Santana ${ }^{2}$, Giselda Bezerra Correia Neves ${ }^{1}$.

\section{RESUMO}

Objetivo: Descrever, a partir de uma revisão narrativa, as normas de biossegurança e as medidas que foram adotadas para redução dos riscos inerentes as atividades assistenciais ao paciente em centro cirúrgico, suspeitos ou confirmados de Covid-19. Revisão bibliográfica: Nos centros cirúrgicos, os ricos de infecção nos profissionais de saúde são elevados, por consequência da grande manipulação de vias aéreas e procedimentos anestésicos. Em nível mundial, as instituições estão se mobilizando e construindo protocolos de segurança para o atendimento aos pacientes com suspeita ou portadores de Covid-19, considerando como principal via de transmissão o contato das vias aéreas, porgotículas ou aerossóis. Para promover a segurança dos profissionais e pacientes medidas de biossegurança devem ser adotadas, tais como: a utilização de máscara N95 e uso de boas praticas, a exemplo da paramentação e desparamentação. Considerações finais: A adesão as normas de biossegurança reduzem os riscos decorrente das atividades assistenciais dos profissionais de saúde, devendo ser de caráter coletivo, a fim de proporciona a segurança da equipe e do paciente.

Palavras-chave: Centro cirúrgico, COVID-19, Segurança.

\begin{abstract}
Objective: To describe, from a narrative review, the biosafety standards and the measures that were adopted to reduce the inherent risks the patient's care activities in the operating room, suspected or confirmed of Covid19. Bibliographic review: In surgical centers, the rich of infection in health professionals are high, as a result of the major manipulation of the airways and anesthetic procedures. At the global level, institutions are mobilizing and building safety protocols for the care of patients with suspected or carriers of Covid-19, considering as the main route of transmission the contact of the airways, droplets or aerosols. To promote the saf ety of professionals and patients biosafety measures should be adopted, such as: the use of N95 mask and use of good practices, such as paramentation and disparamentation. Final considerations: The compliance with biosaf ety standards reduces the risks arising from the care activities of health professionals, should be of a collective nature, in order to provide the saf ety of the team and the patient.
\end{abstract}

Key words: Surgical center, COVID-19, Security.

\section{RESUMEN}

Objetivo: Describir, a partir de una revisión narrativa, los estándares de bioseguridad y las medidas que fueron adoptado para reducir los riesgos inherentes a las actividades asistenciales del paciente en quirófano, sospechosos o confirmados de Covid-19. Revisión de la literatura: En los centros quirúrgicos, la riqueza de la infección en los profesionales de la salud es alta, como resultado de la manipulación importante de las vías respiratorias y los procedimientos anestésicos. A nivel mundial, las instituciones están movilizando y

${ }^{1}$ Centro Universitário Brasileiro (UNIBRA), Recife - PE. *E-mail: lucasribeirof16@gmail.com
${ }^{2}$ Unidade de Apoio ao Diabético e Oxigenoterapia Hiperbárica (UNIAD), Caruaru - PE.

SUBMETIDO EM: 12/2021

ACEITO EM: 12/2021

PUBLICADO EM: 1/2022 
construyendo protocolos de seguridad para la atención de pacientes con sospecha o portadores de Covid-19, considerando el contacto con las vías respiratorias, las gotitas o los aerosoles como la principal vía de transmisión. Para promover la seguridad de los profesionales y pacientes se deben adoptar medidas de bioseguridad, tales como: el uso de mascarilla N95 y el uso de buenas prácticas, como la paramentación y la menosprecio. Consideraciones finales: El cumplimiento de las normas de bioseguridad reduce los riesgos derivados de las actividades asistenciales de los profesionales sanitarios, deben ser de carácter colectivo, con el fin de proporcionar la seguridad del equipo y del paciente.

Palabras clave: Centro quirúrgico, COVID-19, Seguridad.

\section{INTRODUÇÃO}

A Covid-19, doença causada pelo Corona vírus denominado Síndrome Respiratória Aguda Grave do Coronavírus 2 (SARS-CoV-2), à princípio foi identificada na China, no mês de dezembro no ano 2019. Em 30 de janeiro de 2020, a Organização Mundial da Saúde (OMS) foi declarada a epidemia da Covid-19 constituindo uma Emergência de Saúde Pública de Importância Internacional (ESPII), em 11 de março de 2020, anunciou a pandemia (OLIVEIRA KW, et al., 2020).

O Vírus manifesta subsistência em aerossóis e superfícies, sendo disseminado por gotículas em suspensão e por fômites, com elevado potencial de infecção, podendo permanecer horas ou até dias em superfícies plásticas, aço inoxidável, papelão e cobre. A concentração do inoculo e os cenários ambientais tais como temperatura e umidade podem modificar a duração da ef etividade das partículas virais. Pacientes sintomáticos podem desenvolver maior carga viral e determinados procedimentos médicos podem colaborar com a concepção de aerossóis (CUNHA AG, et al., 2020).

Para Oliveira TC (2020), nos centros cirúrgicos, a possibilidade de contágio entre os próprios pacientes e os profissionais são elevadas, por consequência da grande manipulação de vias aéreas, procedimentos anestésicos e dificuldades de comunicação entre os membros da equipe. $O$ cenário de risco exige interdependência entre o cuidado cirúrgico, prevenção e controle de infecções, notadamente a Covid-19 e segurança do paciente, contribuindo para a interseção de áreas sensíveis à qualidade dos serviços de saúde.

A Biossegurança em sua finalidade mais ampla está vinculada em diferentes áreas, dentre as quais se destaca a saúde, onde o risco biológico está presente ou concebe uma ameaça potencial. Consequentemente, a Biossegurança pode ser definida como uma soma de medidas e procedimentos técnicos, fundamentais para o manuseio de agentes e materiais biológicos suficientes para prevenção, redução, controle ou eliminação dos riscos intrínsecos às atividades que possam ser prejudicial á saúde humana, animal, vegetal e ao meio ambiente (MINISTÉRIO DA SAÚDE, 2017).

Diante disso, objetivou-se com este estudo descrever, a partir de uma revisão narrativa, as normas de biossegurança e as medidas que foram adotadas para promover a redução dos riscos inerentes às atividades assistenciais ao paciente em centro cirúrgico, suspeitos ou confirmados de Covid-19. Além de apontar algumas características a respeito da Covid-19.

\section{REVISÃO BIBLIOGRÁFICA}

\section{Norma Regulamentadora - NR 32}

Define as diretrizes básicas para a elaboração de normas de proteção à segurança das equipes que compõem os serviços de saúde, tal como daqueles que executam atividades de promoção e assistência à saúde em geral. Com a finalidade de aplicação desta Norma Regulamentadora (NR) classifica-se Risco Biológico a possibilidade da exposição ocupacional a agentes biológicos do Programa de Prevenção de Riscos Ambientais (PPRA), além do mais, na NR-09, na fase de reconhecimento, deve abranger: Identificação dos riscos biológicos que corroboram, em conformidade com a localização geográfica e da representação do serviço de saúde e seus setores e avaliação do local de trabalho e do trabalhador (MINISTÉRIO DA SAÚDE, 2020). 
Para Agência Nacional de Vigilância Sanitária (ANVISA) previamente a um procedimento cirúrgico é indispensável ter a certeza que existem Equipamentos de Proteção Individual (EPI) disponível para todos os profissionais e que sejam adequados para o atendimento de pacientes suspeitos ou positivados de Covid-19 (MINISTÉRIO DA SAÚDE, 2021).

Em nível global, as instituições de saúde estão se mobilizando e determinando protocolos de segurança para o atendimento aos pacientes suspeitos ou portadores da Covid-19, considerando como principal via de transmissão o contato das vias aéreas, por gotículas ou aerossóis. $O$ artificio de manipulação do trato respiratório, como intubação, aspiração endotraqueal e extubação, abrangendo aerossolização de partículas, devendo ser classificados como de alto risco e por inf ectar os profissionais da saúde (TREVILATO DD, et al., 2020).

Para organização do Centro Cirúrgico de todo o Brasil durante a pandemia da Covid-19, uma junção de discussões sobre as orientações da comunidade científica mundial indica para a suspensão de procedimentos eletivos, com a proposta de redução do contingente de circulação nas instituições e priorizando os pacientes de procedimentos em urgência, emergência e oncológicos (TREVILATO AD, et al., 2020).

\section{Suporte para os profissionais}

De acordo com a ANVISA, previamente ante um procedimento cirúrgico é imprescindível que toda equipe tenha a convicção da disponibilidade dos Equipamentos de Proteção Individual (EPI) acessível a toda a equipe e que se encontre em boas condições para o atendimento de pacientes suspeitos ou confirmados de COVID-19 (MINISTÉRIO DA SAÚDE, 2021).

Segundo Busanello J, et al. (2020), a garantia da força de trabalho qualificada para atender a demanda pandêmica é indispensável para estabelecer estratégias de apoio aos profissionais da saúde. A complexidade clínica da Covid-19 potencializou a capacitação, por meio de simulações práticas sobre biossegurança e protocolos de tratamento. Em contrapartida, há preocupação por conta da insuficiência e/ou inadequação dos EPI.

Destaca-se nesse contexto a importância da vigilância à saúde do trabalhador, com ênfase nas ações para a avaliação diária das condições de saúde, incluindo sinais e sintomas da Covid-19, bem como outras doenças relacionadas ao trabalho ocupacional a nível biológico e psicossocial. O acompanhamento dos profissionais é apontado como uma das ações mais ef etivas para a manutenção dos trabalhadores da saúde no enfrentamento da pandemia, já que estes são fundamentais para o pleno funcionamento dos serviços de saúde. (BUSANELLO J, et al., 2020).

\section{Aspectos organizacionais em cirurgia de emergência}

De acordo com o estudo de Aranda-Narvaés MJ, et al. (2020), recomenda-se ter uma sala cirúrgica exclusiva para pacientes com Covid-19 confirmados ou altamente suspeitos, sem possibilidade de confirmação por se tratar de patologias não tardias. É necessário criar um circuito de transferência específico que deve ser o mais direto e curto possível, tomando medidas de prevenção e segurança específicas: uso de elevadores e áreas específicas, áreas de passagem livres, colocação de panos com água sanitária nas passagens, limpeza posterior adequada, durante o procedimento medidas cautelar devem ser tomadas.

O diálogo entre os membros da equipe deve sempre ser eficaz para prevenir situações adversas e a eventual de contaminação pela SARS-CoV-2. É indispensável a elaboração de protocolos e checklists característicos (indica-se ao mínimo, o Protocolo de Cirurgia Segura - Lista de verificação de segurança cirúrgica e um protocolo para paramentação e desparamentação de EPIs) com a finalidade de aperfeiçoar a intensidade de trabalho e prevenir contaminações e outros eventos adversos (MINISTERIO DA SAÚDE, 2021).

Recomenda- se a adesão de uma lista de verificação de itens essenciais que necessitarão permanecer dentro do centro cirúrgico (equipamentos e insumos), a ser verificado juntamente com a equipe médica antecipando o chamado do paciente ao seguir para o centro cirúrgico. Com a finalidade de garantir qualificação das equipes para a implementação dos protocolos assim como frequente verificação de seu seguimento por parte dos profissionais (MINISTERIO DA SAÚDE, 2021) 


\section{Precauções para a intervenção de um paciente Covid-19 positivo}

No caso de um paciente com resultado positivo confirmado, o EPI deve ser usado junto com a roupa cirúrgica para garantir a proteção adequada para o pessoal da sala de cirurgia. Mesmo em casos não confirmados, no atual contexto de pandemia, deve-se presumir que todos os pacientes são positivos e tomam as mesmas medidas de proteção para evitar a exposição (BALIBREA MJ, et al., 2020).

Perante uma exposição sem uso de EPI a um paciente sob investigação, atestável ou evidenciada de contágio por coronavírus, o profissional que se expor tem que ser visto como contato próximo e será tratado como tal, em concordância com as medidas específicas de cada centro. Todos os profissionais expostos necessitam entrar em contato imediatamente com o serviço de Medicina preventiva, saúde ocupacional, prevenção de riscos ocupacionais em seu centro para seguir as orientações adequadas (BALIBREA MJ, et al., 2020).

Com intuito de concentrar e integralizar os achados referentes as medidas de biossegurança na assistência ao paciente em centro cirúrgico, foi construído com base nas normas preconizadas pela ANVISA, um quadro síntese com as indicações para uso de EPI (Quadro 1).

Quadro 1 - Indicação de Equipamentos de Proteção Individual (EPI) para as equipes do centro cirúrgico.

\begin{tabular}{|l|l|}
\hline \multicolumn{1}{|c|}{ Situação } & \multicolumn{1}{|c|}{$\begin{array}{c}\text { Equipe do Centro cirúrgico Equipamentos de Proteção } \\
\text { Individual (EPI) }\end{array}$} \\
\hline $\begin{array}{l}\text { Triagem de sintomas respiratórios ou } \\
\text { exame de reação da transcriptase } \\
\text { reversa seguida pela reação em cadeia } \\
\text { da polimerase (RT-PCR) disponíveis e } \\
\text { o paciente é sintomático ou suspeito ou } \\
\text { confirmado de Covid-19 }\end{array}$ & $\begin{array}{l}\text { Equipe Cirúrgica: Máscara N95/PFF2 ou equivalente Protetor } \\
\text { facial ou óculos de proteção, gorro descartável, Avental cirúrgico, } \\
\text { Luvas estéreis. Anestesista: Máscara N95/PFF2 ou equivalente } \\
\text { Protetor facial ou óculos de proteção, Gorro descartável, Avental, } \\
\text { Luvas. }\end{array}$ \\
\hline $\begin{array}{l}\text { Triagem de sintomas respiratórios } \\
\text { disponível e o paciente é assintomático } \\
\text { ou exame de RT-PCR pré-operatório } \\
\text { negativo (quando disponível) }\end{array}$ & $\begin{array}{l}\text { Para cirurgia sem risco de aerossolização: Equipe Cirúrgica: } \\
\text { Gorro descartável, Máscara cirúrgica, Protetor facial ou óculos de } \\
\text { proteção, Avental cirúrgico, Luvas estéreis. Anestesista: Gorro } \\
\text { descartável, Máscara cirúrgica, Protetor facial ou óculos de } \\
\text { proteção, Avental e Luvas. }\end{array}$ \\
\hline $\begin{array}{l}\text { Para situaçães com risco de } \\
\text { aerossolização }\end{array}$ & $\begin{array}{l}\text { Equipe de internação cirurgica Cirúrgica: Gorro, Máscara } \\
\text { N95/PFF2 ou equivalente, Protetor facial ou óculos de proteção, } \\
\text { Avental cirúrgico, Luvas estéreis. }\end{array}$ \\
\hline $\begin{array}{l}\text { Situações de emergência com triagem } \\
\text { de sintomas respiratório não disponível } \\
\text { antes do procedimento }\end{array}$ & $\begin{array}{l}\text { Equipe Cirúrgica: Máscara N95/PFF2, Protetor facial ou óculos } \\
\text { de proteção, Gorro descartável, Avental cirúrgico, Luvas estéreis. } \\
\text { Anestesista: Máscara N95/PFF2 ou equivalente Protetor facial } \\
\text { ou óculos de proteção, Gorro descartável, Avental e Luvas }\end{array}$ \\
\hline
\end{tabular}

Fonte: Freitas RL, et al., 2021; dados extraídos do Ministério da Saúde, 2021.

A equipe multidisciplinar que compõe a sala cirúrgica devem usar EPIs, a decorrer da situação de risco, conforme recomendado na Nota Técnica ํㅡ 04/2020. Máscaras de tecido não são EPls, e por essa razão, não devem ser manuseadas pela equipe de saúde ao longo da assistência direta aos pacientes. É contraindicado utilizar máscaras N95/PFF2 ou semelhante que disponha de válvula de expiração durante os procedimentos cirúrgicos. Essas válvulas permitem a saída do ar expirado pelos profissionais que está utilizando esse EPI e pode contaminar o campo cirúrgico, pacientes e demais profissionais. O paciente deve fazer uso da máscara cirúrgica, para monitorização de fonte, no decorrer do seu deslocamento ao centro cirúrgico, ao descolar-se pela sala de anestesias e para o leito de internação após o procedimento (MINISTERIO DA SAÚDE, 2021).

\section{Desparamentação}

O estudo de Cunha GA, et al. (2020) corrobora com os achados dessa pesquisa pois aborda acerca da desparamentação, tendo em vista que a realização da desparamentação de forma correta minimiza de forma significativa a chance de os profissionais de saúde serem contaminados. Todos os EPls, incluindo as máscaras N95, devem ser descartados (de preferência na antessala) após a utilização durante a realização 
das intervenções que geram aerossóis (intubação, extubação, aspiração, ressuscitação cardiopulmonar, ventilação não invasiva e broncoscopia), com exceção dos óculos, protetor facial e sapatos impermeáveis. Não tocar o rosto ou couro cabeludo antes da higiene completa das mãos. Dirigir se ao vestiário para banho de aspersão. Efetuar a limpeza dos óculos de proteção utilizando água e sabão, enxugar e aplicar álcool a $70 \%$.

\section{Preparo da sala de procedimento}

Aconselha-se utilizar a mesma sala cirúrgica para atendimento a pacientes com suspeita ou confirmação de Covid-19 até o fim da pandemia e garantir que um intervalo mínimo de agendamento de uma hora entre os procedimentos, tempo este destinado aos cuidados com higienização. Procedimentos com geração de aerossóis, como intubação, devem ser realizados, preferencialmente, em sala com pressão negativa ou arcondicionado desligado (pressão neutra) (TREVILATO DD, et al., 2020).

A Associação Brasileira de Enfermeiros de Centro Cirúrgico, Recuperação Anestésica e Centro de Material e Esterilização (SOBECC) preconizam intervenções para o preparo da sala de procedimentos, dentre as principais orientações incluem-se: Instantaneamente higienizar as mãos para que se inicie o preparo da sala. Seguir a organização da sala, em conformidade com protocolo de precaução de contato e aerossóis. Viabilizar, havendo condições, tubo para intubação com circuito fechado para aspiração de vias aéreas, evitando aerossolização do vírus. Apenas equipamentos, mobiliários e medicamentos indispensáveis devem ser levados para sala de procedimentos. Garantindo o uso do filtro bacteriano/viral em três pontos do circuito de anestesia (SOBECC, 2020).

A higienização da sala deve ser executada seguidamente após a retirada do paciente. Na desmontagem, é indicada a utilização de duas luvas, precisando a primeira luva ser trocada de imediato ao entrar em conta to com material infectado. A equipe de enfermagem tem a função de sistematizar instrumentais em recipientes plásticos hermeticamente fechados e com sua devida identificação, para prevenção de possíveis infecções, e encaminhar ao centro de materiais e esterilização da instituição (TREVILATO DD, 2020).

A organização do método de limpeza tende a ser unidirecional, isto é, do local mais limpo ao mais sujo. Após a higiene de equipamentos e superfícies, precisar ser realizada limpeza final pela equipe de higienização. É indicado instituir uma lista de verificação, tipo checklist, de forma a padronizar e certificar que todos os procedimentos de limpeza foram cumpridos (TREVILATO DD, 2020).

\section{Medidas intraoperatórias}

De acordo com o estudo de Estévez MJ, et al. (2021), o SARS-CoV-2 pode sobreviver por pelo menos 3 dias em uma variedade de materiais comumente encontrados em salas de cirurgia (aço inoxidável, plástico). As fortes evidências geradas pelas publicações dos últimos 12 anos indicam que uma abordagem multimodal é necessária para minimizar o alto risco de eventos de transmissão de patógenos no intraoperatório. A higiene das mãos, limpeza do ambiente, cuidados com cateteres vasculares (arteriais e venosos), descolonização do paciente e otimização da vigilância devem ser melhorados.

Disponibilizar dispensadores com desinfetante à base de hidroalcoólico nas imediações da área de trabalho do anestesiologista, dispor de bolsas hermeticamente fechadas para posicionar todo o material contaminado no decorrer da indução, limpar diligentemente a área de trabalho posteriormente a indução anestésica e depois de cada manejo com lenços desinfetantes são precauções fundamentais para preservar um local de trabalho seguro e livre de contaminação (ESTÉVEZ MJ, et al., 2020).

Ao longo da indução e, sobretudo nas emergências anestésicas, é elevado o número de manobras desempenhadas no local dos pacientes que manifestam alto risco de transmissão viral ou bacteriana; Aproximadamente 350 possíveis atos de contaminação foram quantificados ao longo do procedimento intraoperatório de rotina de um paciente (ESTÉVEZ MJ, et al., 2020).

\section{Identificar procedimentos de alto risco}

Para que ocorra a minimização de riscos assistências no centro cirúrgico é necessária a identificação de procedimentos com elevado risco de propiciar aerossóis, que requerem cautela respiratória. Alguns 
procedimentos cirúrgicos que podem gerar aerossóis incluem: traqueostomia, broncoscopia rígida, e cirurgia com utilização de instrumento perfurante de alta velocidade. Procedimentos anestésicos que podem produzir aerossóis incluem Ventilação Não Invasiva (VNI), além da intubação e extubação (Quadro 2).

Quadro 2 - Identificação de alguns procedimentos de alto risco cirúrgicos e anestésicos que podem gerar aerossóis.

\begin{tabular}{|c|c|c|c|}
\hline \multicolumn{2}{|r|}{ Cirúrgicos } & \multicolumn{2}{|r|}{ Anestésicos } \\
\hline $\begin{array}{c}\text { Broncoscopia } \\
\text { rígida }\end{array}$ & $\begin{array}{l}\text { Durante o procedimento, as vias } \\
\text { aéreas não estão protegidas. Embora } \\
\text { a glote esteja aberta pelo } \\
\text { broncoscópio e a tosse efetiva não } \\
\text { seja possível, expiração forçadapode } \\
\text { ocorrer quando se permite que o } \\
\text { paciente ventile espontaneamente. }\end{array}$ & $\begin{array}{c}\text { Ventilação } \\
\text { não invasiva }\end{array}$ & $\begin{array}{l}\text { Experimentos com pressão } \\
\text { positiva inspiratória nas vias } \\
\text { aéreas (IPAP) mostraram que, } \\
\text { apesar de máscara ajustada, } \\
\text { pequenas gotas ainda podem } \\
\text { ser dispersas através de } \\
\text { vazamentos. }\end{array}$ \\
\hline Traqueotomia & $\begin{array}{l}\text { Traqueotomia cirúrgica ou troca de } \\
\text { tubo de traqueotomia são } \\
\text { procedimentos com alto risco de } \\
\text { geração de aerossol. }\end{array}$ & $\begin{array}{l}\text { Intubação e } \\
\text { extubação }\end{array}$ & $\begin{array}{l}\text { A geração de aerossol é um risco } \\
\text { se o paciente não estiver } \\
\text { totalmente paralisado durante a } \\
\text { intubação. A extubação } \\
\text { geralmente induz tosse, que } \\
\text { pode gerar aerossóis. }\end{array}$ \\
\hline $\begin{array}{l}\text { Cirurgia } \\
\text { envolvendo } \\
\text { perfuração de } \\
\text { alta velocidade }\end{array}$ & $\begin{array}{l}\text { Os dispositivos de alta velocidade } \\
\text { utilizados em cirurgias dentárias e } \\
\text { ortopédicas mostraram-se capazes } \\
\text { de gerar uma nuvem de aerossol que } \\
\text { poderia contaminar o ambiente da } \\
\text { sala cirúrgica. }\end{array}$ & $\begin{array}{c}\text { Reanimação } \\
\text { Cardiopulmo } \\
\text { nar (RCP) }\end{array}$ & $\begin{array}{l}\text { A RCP foi identificadacomo uma } \\
\text { causa de infecção por SARS } \\
\text { disseminada pelos profissionais } \\
\text { de saúde, pois envolve } \\
\text { ventilação sob máscara, } \\
\text { aspiração das vias aéreas e } \\
\text { intubação. }\end{array}$ \\
\hline
\end{tabular}

Fonte: Freitas LR, et al., 2021; dados extraídos de Tang G, et al., 2020 e Skoog H, et al., 2020.

Para promover as medidas de biossegurança é necessário que as instituições de saúde atuem mediante o planejamento devendo ser baseado em protocolos com reforço de cuidados e orientações. Uma ferramenta positiva para as melhorias na segurança do paciente e dos profissionais éa listas de verificação de seg urança cirúrgica, propostas pela OMS. Vários estudos mostraram o ef eito positivo das listas de verificação no centro cirúrgico, incluindo eficácia na redução de infecções relacionadas a cateter central, redução de erros de tratamento e melhora na comunicação. Portanto, as listas de verificação também podem padronizar as tarefas clínicas e ajudar os profissionais de saúde a adotar bons comportamentos em um cenário de alto estresse durante a pandemia de COVID-19 (HUANG J, et al., 2020).

Para Poveda BV, et al. (2020), as instituições de saúde realizam papel fundamental na instrução educacional dos profissionais que compõe a equipe de saúde, concedendo subsídios para implementar o uso de instrumentos nos cuidados na rotina diária e salientando a importância da utilização das medidas de segurança. A implementação bem-sucedida da lista de verificação está associada à promoção de treinamento e material de aprendizagem, aperfeiçoamento de lideranças para acompanhamento contínuo e auditoria da utilização do checklist, entendimento no papel de cada profissional da equipe e suporte para análise da real eficácia da ef etivação do checklist.

\section{Medidas pós-operatória em paciente suspeito ou infectado com SARS-CoV-2}

Paciente em recuperação, após realizar o procedimento deverá manter-se com a máscara cirúrgica e, se porventura houver necessidade de oxigênio complementar, o cateter de oxigênio precisará permanecer sob 
a máscara. Suporte não invasivo de vias aéreas com pressão positiva tem que ser evitado ao máximo, pois pode propiciar a aerossolização do vírus. Quando o paciente se encontra em condições de alta anestésica, deve-se utilizar máscara cirúrgica para o transporte, e os profissionais que irão realizar o transporte precisarão utilizar os EPI's, de acordo com as recomend ações de uso nas suspeitas de Covid-19 (CUNHA AG, et al., 2020).

\section{CONSIDERAÇÕES FINAIS}

A Covid-19 mudou o cenário epidemiológico mundial e exige da sociedade medidas urgentes de adaptação, um dos principais desafios para a assistência ao paciente em casos suspeito ou confirmado de Covid-19 refere se às medidas de proteção individual a serem adotadas pelos profissionais de saúde, tendo em vista que a realização de cirurgias em pacientes com diagnóstico positivo aumenta o risco de complicações pós-operatórias e os procedimentos apresentam riscos para os profissionais, a adesão às normas de biossegurança reduz os riscos inerentes as atividades assistenciais, sendo assim, o uso de boas práticas nos serviços devem ser de caráter coletivo, proporcionando a segurança da equipe e do paciente.

\section{AGRADECIMENTOS}

Agradecemos a bolsa concedida para autora Giselda Bezerra Correia Neves - Ao "Ministério da Ciência, Tecnologia, Inovações e Comunicações" (MCTIC). Ao "Conselho Nacional de Desenvolvimento Científico e Tecnológico" (CNPQ). Bolsista Industrial Tecnológico DTI-A CNPq, pesquisadora do ministério da educação. Número de concessão da bolsa: 304424/2020-0, Modalidade: Desenvolvimento Tecnológico Industria (DTIA).

\section{REFERÊNCIAS}

1. ARANDA-NARVÁEZ MJ, et al. Atención de la urgencia quirúrgica durante la pandemia COVID-19. Recomendaciones de la Asociación Española de Cirujanos. Revista Elsevier, 2020; 98 (8): 433-441.

2. ASSOCIAÇÃO BRASILEIRA DE ENFERMEIROS DE CENTRO CIRÚRGICO, RECUPERAÇÃO ANESTÉSICA E CENTRO DE MATERIAL E ESTERILIZAÇÃO (SOBECC). COVID-19: Recomendações da SOBECC sobre fluxo em cirurgia e endoscopia. 2020. Disponível em: http://www.coren-es.org.br/covid-19-recomendacoes-da-sobecc-sobrefluxo-para-procedimentos-cirurgicos-ou-endoscopicos_21822.html. Acessado em:16 out. 2021.

3. BALIBREA MJ, et al. Manejo quirúrgico de pacientes con infección por COVID-19. Recomendaciones de la Asociación Española de Cirujanos. Revista Elsevier, 2020; 98 (5): 251-259252.

4. BUSANELLO J, et al. Otimização dos cuidados intensivos na assistência ao paciente com COVID-19. Revista Enfermagem foco, 2020;11 (2):32-36.

5. CUNHA GA, et al. Como preparar o centro cirúrgico para pacientes COVID-19. Revista do Colégio Brasileiro de Cirurgiões, 47:e20202575.

6. ESTEVEZ MJ. Medidas de control de la transmisión de infecciones en el entorno quirúrgico: cambio de paradigma tras la covid-19. Revista Espanhola de Anestesiologia e Reanimação, 2020:56-61.

7. HUANG J, et al. Improving staff safety with checklists during novel coronavirus disease (COVID -19) pandemic A quasiexperiment study in vascular surgical department. Medicine open. 2020;99(32):e21548.

8. MINISTÉRIO DA SAUUDE. Manual do Ministério da Saúde. Classificação de risco dos agentes. 2017. Disponível em: https://bvsms.saude.gov.br/bvs/publicacoes/classificacao_risco_agentes_biologicos_3ed.pdf. Acessado em:13 Mai. 2021.

9. MINISTÉRIO DA SAÚDE. Manual do Ministério da Saúde. Cuidados no ambiente de assistência hospitalar ao paciente com suspeita ou diagnóstico de covid-19. 2020. Disponível em: http://conteudosdigitais.eerp.usp.br/covid19/cuidados_covid_ms_05_05_2020.pdf. Acessado em:10 out. 2021.

10. MINISTÉRIO DA SAÚDE. Nota Técnica Agência Nacional de Vigilância Sanitária. Orientações para a prevenção e o controle das infecções pelo novo coronavírus (sars-cov-2) em procedimentos cirúrgicos. 2021. Disponível em: https://www.gov.br/anvisa/pt-br/centraisdeconteudo/publicacoes/servicosdesaude/notas-tecnicas/nota-tecnica-062020-gvims-ggtes-anvisa.pdf/view. Acessado em: 16 out. 2021

11. OLIVEIRA KW, et al. Como o Brasil pode deter a COVID-19. Revista Epidemiologia e Serviços de Saúde. 2020.29 (2): e2020044.

12. POVEDA BV, et al., Implementação de checklist de segurança cirúrgica no Brasil: estudo transversal. Revista Brasileira de Enfermagem, 2021;74(2): e20190874.

13. SKOOG H, et al. Tracheotomy in the SARS-CoV-2 pandemic. Revista Head \& Neck. 2020;42: 1392-1396.

14. TANG G, et al. Manejo perioperatório de casos suspeitos / confirmados de COVID -19. Anaesthesia tutorial of the week. 2020;1-13.

15. TREVILATO DD, et al. Centro cirúrgico: recomendações para o atendimento de pacientes com suspeita ou portadores de covid-19. Revista Associação Brasileira de Enfermeiros de Centro Cirúrgico, Recuperação Anestésica e Centro de Material e Esterilização (SỎBECC). 2020;25(3): 187-193. 